\title{
Sociología
}

Natalucci, A. (2018). La gramática movimentista durante el giro a la izquierda: El caso de Argentina. Revista de Sociología 33(1), 88-103. doi: 10.535/0719529X.2018.51796

\section{La gramática movimentista durante el giro a la izquierda: El caso de Argentina}

\author{
[The movementist grammar during the left turn: The case of \\ Argentina]
}

Ana Natalucci (1)

CONICET / Universidad de Buenos Aires / Instituto de Investigaciones Gino Germani

\begin{abstract}
Resumen
Durante el giro a la izquierda uno de los cambios producidos tuvo relación con la capacidad articulatoria de los gobiernos. En Argentina, estos cambios se expresaron en la recreación de la gramática movimentista de acción que implicó la conformación de un movimiento político entre la elite, organizaciones sociales y sindicales. El objetivo de este ensayo es analizar esa capacidad de articulación política, atendiendo a la formación y consolidación del vínculo entre el kirchnerismo y las organizaciones. El argumento central es que esa gramática se constituyó en 2003, se consolidó entre 2007 y 2010 y fue desarticulándose desde 2010. Las organizaciones y la elite tenían consensos estratégicos y programáticos, pero esta mantuvo una lógica de concentración del poder, por lo que la gramática movimentista tuvo una baja institucionalización. Este ensayo reúne las conclusiones de un proyecto internacional cuyo objetivo fue analizar el fin del giro a la izquierda en América Latina.
\end{abstract}

Palabras clave: giro a la izquierda, gramática movimentista, kirchnerismo, organizaciones sociales, organizaciones sindicales

\begin{abstract}
During the left turn in Argentina, one of the notable changes that took place concerned the articulatory capacity of the government. This change was expressed through the re-creation of movementist grammar and occurred alongside the formation of a political movement that involved social and union organizations and the elite. The objective of the present article is to analyze political articulation in the context of the formation and consolidation of relationships between Kirchnerism and such organizations. The central assertion is that this grammar began to develop in 2003, constituted a standard in the discourse between 2007 and 2010, and has since fallen into disuse. The organizations and the elite implemented a number of strategic and programmatic agreements, but given the focus of these on concentration of power, movementist grammar suffered from low levels of institutionalization. The present article brings together the conclusions of an international project which sought to analyze the end of the left turn in Latin America.
\end{abstract}

Keywords: left turn, movementist grammar, kirchnerism, social organizations, workers' organizations

Contacto: La comunicación sobre este artículo debe ser enviada a Ana Natalucci, email: anatalucci@sociales.uba.ar Financiamiento: La autora agradece el financiamiento por parte de University of Bath, Reino Unido. 


\section{INTRODUCCIÓN}

En los inicios del siglo XXI, y luego de las crisis neoliberales, se impulsó en algunos países sudamericanos un giro a la izquierda, entre ellos Brasil, Venezuela, Argentina, Bolivia, Ecuador, Uruguay. En el debate académico se han discutido los significados y sentidos de ese giro. Autores como Álvarez, Rubin, Thayer, Baiocchi, y Laó-Montes (2017) hablaron de pink tide para referirse a un rojo lavado en el sentido de una izquierda no revolucionaria. Otros como Silva (2017) o Rossi (2017) han referido como un giro a la izquierda al proceso de reincorporación de los sectores populares luego de los procesos de exclusión neoliberal. Finalmente, Ferrero, Natalucci y Tatagiba (En prensa) postulan que ese giro a la izquierda se constituyó a partir de la recreación de una dinámica sociopolítica donde se refundaron imaginarios sociales, las relaciones entre gobiernos y actores de la sociedad civil dando lugar a nuevas formas de representación. Este ensayo se concentra en el caso de Argentina. En este país, el giro a la izquierda tuvo lugar a partir de 2003 luego de la asunción de Néstor Kirchner como presidente y el establecimiento de un triple pacto: de consumo (por la reactivación del mercado interno), de inclusión social (viabilizado por políticas sociales) y de soberanía (autonomía frente a Estados Unidos y nuevos alineamientos regionales) (Stefanoni, 2016). Durante este giro hubo tres novedades en la dinámica sociopolítica: la capacidad de innovación política, de incorporación a los sectores populares y medios y de articulación política (Ferrero et al., En prensa).

Haciendo un breve racconto, Néstor Kirchner asumió la presidencia de Argentina con un bajo caudal electoral (22.2\%). Siguiendo a Torre (2005), esto constituyó un déficit fundacional de apoyo; para Cheresky (2006) determinó la necesidad de construir un electorado postelectoral, razón por la cual organizaciones sociales y sindicales fueron convocadas. Esta condición constitutiva fue determinante para que paralelamente $-y$ a veces cruzado con la gestión gubernamental- se impulsara la construcción de un movimiento político. Al respecto, Sidicaro (2011) propone distinguir la gestión gubernamental "del conjunto heterogéneo de sectores políticos e ideas identificado con el presidente Néstor Kirchner y con su sucesora y esposa Cristina Fernández" (p. 83).

La construcción de ese movimiento se realizó de acuerdo con una gramática movimentista de acción política. Entre sus objetivos estaban consolidar la base electoral del kirchnerismo, compensar el poder del partido justicialista en la estructura gubernamental (Gómez, 2010) y aprovechar la capacidad de movilización de las organizaciones de base territorial (sociales o piqueteras) y sindicatos. A su vez, estas obtuvieron influencia y participación en el proceso político (Gómez, 2009). A lo largo de este proceso, las organizaciones territoriales transformaron sus dinámicas e identidades, mientras las sindicales se revitalizaron respecto de los intercambios corporativos y las formas de hacer política.

De este modo cabe preguntarse ¿qué implicancias tuvo la articulación política durante el giro a la izquierda que dio como resultado la recreación de esa gramática movimentista? ¿Cómo se produjo el acercamiento y la 
Natalucci, A. (2018). La gramática movimentista durante el giro a la izquierda: El caso de Argentina. Revista de Sociología 33(1), 88-103. doi: 10.535/0719529X.2018.51796

consolidación del vínculo entre el kirchnerismo y las organizaciones de diversos tipos? En el marco de estos debates, este ensayo se centra en una de esas tres novedades de la dinámica sociopolítica durante el giro a la izquierda que, aunque no es restrictivo a Argentina, cobró algunas particularidades sobre las que detenernos. Esta es, la articulación política y su relación con la recreación de la gramática movimentista de acción política.

El argumento central es que esa gramática se constituyó a partir de 2003 y se consolidó entre 2007 y 2010. A diferencia del peronismo clásico, esta recreación se construyó sobre una suerte de convite de la elite política a organizaciones, con las que tenían puntos de consensos estratégicos y programáticos. Como esas organizaciones no eran consideradas fuerza propia, la élite política mantuvo una lógica decisionista. Esta fue una de las razones por las cuales la recreación de la gramática movimentista tuvo una baja institucionalización. Entre 2010 y 2015, luego del fallecimiento de Kirchner, esa gramática movimentista fue desarticulándose debido al intento de la élite de ampliar la fuerza propia, que en muchos casos se erigió en relación de competencia a las organizaciones ya existentes. Así se configuró un escenario de progresivo desplazamiento de las organizaciones, que llevó a una contracción de la base de alianzas y contribuyó a la derrota en las elecciones parciales de 2013 y las generales de 2015 en lo que se conoce como la crisis del giro a la izquierda. Como cualquier caso nacional tiene sus particularidades, sin embargo, profundizar sobre este tipo de experiencia es ilustrativo de como el giro a la izquierda reorganizó debates e instituyó nuevas dinámicas socio-políticas. Si pensamos que este tipo de proceso es parte de los ciclos que atraviesan la región, conocerlos permite el establecimiento de perspectivas para entender otros casos nacionales como las diferentes temporalidades regionales.

\section{Breve digresión teórica}

La relación entre un ciclo de movilización y los cambios sobre el régimen político fue planteada originalmente por Germani (1966). Esa transformación societal que llevó a un proceso de modernización en lo social, pero de exclusión en lo político fue decisivo para la constitución de un ciclo de movilización que modificó las reglas del régimen político. De esta manera, el populismo argentino constituyó una expresión de democratización fundamental viabilizada por "la movilización heterónoma de importantes fracciones de las masas en una sociedad sometida a un cambio acelerado" (Pérez, 2007, p. 300).

En la obra de Germani (1978 | 2003), la noción de movilización tiene un valor fundamental como categoría de alcance intermedio. El autor diferencia tipos de participación: integrada y no integrada de la movilización. Esta última supone un exceso respecto de la participación integrada por grado, alcance o forma. Asimismo, distingue la movilización psicológica de la objetiva, esto es la disponibilidad de los agentes a movilizarse de la respuesta activa del comportamiento real. Este pasaje puede ser posibilitado por una élite; la cultura política, las actitudes, la experiencia o el carácter migratorio de las bases. Esas combinaciones posibles son definidas por Germani como regímenes de movilización. Como estrategia de corrimiento de su jerga funcionalista, llamaremos a esos regímenes gramáticas de acción política. 
Natalucci, A. (2018). La gramática movimentista durante el giro a la izquierda: El caso de Argentina. Revista de Sociología 33(1), 88-103. doi: 10.535/0719529X.2018.51796

Inspirada en la perspectiva giddensiana, una gramática de acción política constituye un sistema de reglas de acción que liga el tiempo y espacio de la experiencia de los sujetos, definiendo formas válidas de resolver problemas de los recursos de asignación -derivados del dominio humano sobre la naturaleza- y de autoridad-derivados de las actividades de seres humanos. Un juego de reglas no escritas que delimita, por un lado, las pautas de interacción de los sujetos; y por otro, las combinaciones de acciones para coordinar, articular e impulsar intervenciones públicas, acciones que se dirijan a cuestionar, transformar o ratificar el orden social. Una gramática delinea la manera en que un sujeto colectivo interviene en el espacio público, encuentra motivos de justificación y razones para actuar, establecer estrategias de coordinación y articulación política y propone un modo de ordenamiento social. El análisis de estas gramáticas permite dilucidar los vínculos entre la movilización y los cambios políticos.

Puede haber varios tipos de gramáticas, autonomistas, clasistas (Natalucci, 2015a), en este ensayo nos concentramos en la gramática movimentista. Esta no es nueva en la cultura política nacional, sino que se constituyó a partir de la integración de los sectores populares al Estado nacional a mediados de los cuarenta combinando la representación corporativa con la apelación a un lenguaje de derechos. Con una concepción circular de la historia alternada entre momentos de resistencia -de retroceso económico y de fragmentación política para los sectores populares- y de ofensiva -de recuperación de derechos, de articulación organizacional y acceso al Estado- la movilización es pensada como una estrategia de cuestionamiento social en los momentos defensivos y plebiscitaria y de apoyo a los gobiernos afines en los momentos ofensivos. De raigambre en la tradición nacional-popular, la expectativa de las organizaciones es la construcción de un movimiento nacional que impulse un proyecto policlasista, donde tengan la posibilidad de oficiar de puentes entre los sectores populares a los que aspiran a representar y el Estado. Ese movimiento nacional suele articularse con una élite externa que contribuye a la integración de las demandas en el régimen político y así al impulso de una agenda de cambios.

La productividad de esta conceptualización sintética entre las perspectivas de Germani y Giddens radica en que permite pensar el proceso de las organizaciones sociales y sindicales, sin enfatizar exclusivamente en dimensiones intencionales, estructurales o funcionales. En este sentido, las organizaciones no son equiparables a las gramáticas, sino que estas permiten definir el campo político y sus interacciones en él.

\section{La invitación movimentista}

El kirchnerismo como movimiento político se constituyó desde junio de 2003 bajo el liderazgo de Kirchner; se integró por una élite -nucleada en el Frente Para la Victoria (FPV) y compuesta por el Partido Justicialista y el Grupo Calafate-, organizaciones con representación en los trabajadores formales -como el Movimiento de Trabajadores Argentinos (MTA) perteneciente a la Confederación General del Trabajo (CGT) - y de base territorial en representación de los trabajadores desocupados e informales -como Barrios de Pie, la Federación de Tierra, Vivienda y Hábitat (FTV) y el Movimiento de 
Natalucci, A. (2018). La gramática movimentista durante el giro a la izquierda: El caso de Argentina. Revista de Sociología 33(1), 88-103. doi: 10.535/0719529X.2018.51796

Trabajadores Desocupados Evita (MTD Evita)-. Una característica común a la elite y a las organizaciones es que estaban integradas por profesionales de la política de tiempo completo, viven de y para la política (Offerlé, 2011).

Cuando Kirchner acordó con el entonces presidente provisional Eduardo Duhalde ser el candidato del Partido Justicialista en las elecciones de 2003 era el gobernador de una provincia periférica, Santa Cruz. Su plataforma política era el Grupo Calafate, conformado en 1998 a partir de la integración de grupos territoriales del Partido Justicialista de la provincia de Buenos Aires y de dirigentes que intentaban encontrar una opción política al modelo económico de la convertibilidad. Una amalgama de organizaciones con despliegue territorial y dirigentes con representación institucional. Sobre la base de este grupo se formó en 2003 el FPV que reunía básicamente al frente para la victoria Santacruceña y al partido justicialista, sustentado sobre una voluntad frentista que el kirchnerismo acuñó desde sus orígenes.

El liderazgo de Kirchner se construyó sobre la figura del pingüino, una autodenominación para instalar un origen outsider de las estructuras tradicionales de poder y de lejanía territorial de los centros políticos. La construcción del FPV se erigió sobre este fuerte liderazgo desmereciendo de alguna manera las mediaciones internas, entendiendo por tales, los "mecanismos de selección de representantes, de competencia interna, de reglas que regulen la competencia en el interior del colectivo político" (Sosa, 2016, pp. 85-86). Esa característica llevó a una organización partidaria concentrada con un fuerte decisionismo de su cúpula (Pérez \& Natalucci, 2012).
Kirchner sabía de su debilidad de origen no solo por su escaso caudal electoral sino también por lo acotado de su apoyo político-partidario. En esta dirección, realizó una amplia convocatoria a la coalición de gobierno. Así, la élite kirchnerista realizó un convite movimentista a organizaciones a las que no consideraba propias en el sentido que no mantenían una relación orgánica; pero con las que tenía consensos programáticos y estratégicos. En términos de su dinámica interna, la interior del movimiento la élite conservaba el poder de veto, algo así como el derecho de admisión, al tener el control de los poderes públicos concentrados en el Estado.

Esta dinámica se quebró a propósito del fallecimiento de Kirchner en octubre de 2010. Ese liderazgo que había construido al interior del movimiento no era fácilmente transferible a Cristina Fernández de Kirchner, presidente de Argentina desde 2007. A estas cuestiones internas se agregaron tensiones políticas internas debido a la crisis internacional de 2008 y 2009 y la ruptura de la situación conocida como win-win, por la simultánea recomposición de las ganancias, del empleo y de los salarios (Wainer, 2018). Ambas cuestiones fueron decisivas para que la elite política pensara como solución la ampliación de la fuerza propia, configurando un escenario de progresivo desplazamiento de las organizaciones. Este proceso es lo que denominamos como desarticulación de la gramática movimentista que implicó la progresiva reducción de la base de alianzas. La dinámica del kirchnerismo como movimiento político no estuvo exclusivamente determinada por el desempeño o las intenciones de su elite, sino también por las experiencias y expectativas de las organizaciones involucradas. ¿Cómo se conformó ese movimiento y de qué maneras 
Natalucci, A. (2018). La gramática movimentista durante el giro a la izquierda: El caso de Argentina. Revista de Sociología 33(1), 88-103. doi: 10.535/0719529X.2018.51796

permitió construir a partir de ese déficit fundacional una legitimidad de ejercicio?

La operación prometeica del kirchnerismo y una nueva posibilidad identificatoria

Aunque el kirchnerismo tuvo un déficit de origen, pudo construir relativamente rápido una legitimidad de ejercicio. En esta construcción fue decisiva una operación prometeica que permitió establecer acuerdos programáticos entre la elite y las organizaciones. Bourdieu (1982) sostuvo que en política decir es hacer, es decir, "hacer creer que se puede hacer lo que se dice y en particular hacer conocer y reconocer principios de división del mundo social" (p. 15). Esa promesa fue expuesta por Kirchner (2003) cuando en su discurso de asunción frente a la asamblea legislativa explicó que entendía por un país normal (su consigna de campaña). Se trataba de un gobierno que se ubicaría por encima de barreras partidarias, un proyecto nacional orientado al Estado de derecho y al bien común desde su rol de articulador social, orientado a la reconstrucción del capitalismo nacional; al desarrollo de políticas de crecimiento económico y protección de los sectores vulnerables, del trabajo, la distribución de la riqueza y la reinstalación de la movilidad social ascendente. Y para todo esto era necesario crear una coalición que pudiera sostenerlo. De ahí que uno de los objetivos centrales del período 20032005 -extendido entre la asunción y las primeras elecciones parciales- fue la constitución de una fuerza política propia kirchnerista peronista y transversal (Kirchner \& Di Tella, 2003).

En la primera semana de junio de 2003, Kirchner mantuvo reuniones con organizaciones de izquierda, autonomistas y del nacionalismo popular, organismos de derechos humanos y centrales sindicales. Allí, por un lado, anunció la creación del gabinete piquetero cuya misión era crear un canal de diálogo directo para la canalización de las demandas de las organizaciones en distintas áreas estatales. Por otro, los convocó a integrarse a la coalición de gobierno en cargos públicos dentro de sus ámbitos de injerencia.

Las organizaciones convocadas tenían capital territorial, entendido como la capacidad de movilizar a sus bases y de crear nuevas demandas a partir de reclamos concretos (Ortiz de Rozas, 2011). En general, eran organizaciones que no tenían votos propios, y que incluso se habían mantenido por fuera del juego electoral, pero contaban con un pasado de lucha contra el neoliberalismo; que le permitía al kirchnerismo construir una frontera política con sus antagonistas, o bien los neoliberales o bien los que querían volver a los noventa en referencia a los gobiernos de Menem. Se trataba de organizaciones con una actividad política continuada, que habían logrado representar demandas en un territorio determinado y ofrecer soluciones consolidando una representación sobre esos sectores. El caso paradigmático fueron las organizaciones piqueteras que habían logrado gestionar una cantidad significativa de planes sociales, comedores y construir un discurso destituyente al modelo neoliberal. Algo parecido sucedió con los núcleos sindicales.

En torno a estos puntos se puede pensar que las relaciones al interior del kirchnerismo no fueron solo instrumentales, sino que implicaron una sofisticada articulación política, fundamentada en una posibilidad identificatoria entendida como las condiciones para releer y actualizar tradiciones políticas (Barros, 2010). Para los 
Natalucci, A. (2018). La gramática movimentista durante el giro a la izquierda: El caso de Argentina. Revista de Sociología 33(1), 88-103. doi: 10.535/0719529X.2018.51796

militantes con experiencias previas, el kirchnerismo significaba la recuperación de la identidad peronista, a la que relacionaban con el período clásico 1945-1955 respecto de la construcción de un Estado con capacidad de intervención sobre la sociedad y la ampliación de derechos.

Organizaciones sociales y sindicales

Las organizaciones que aceptaron la invitación compartían dos cuestiones: tenían un pasado piquetero y se inscribían en la tradición del nacionalismo popular o en la izquierda nacional. A su vez, lo hicieron dirigentes con larga tradición militante, entre ellos, Edgardo Depetri, fundador en 2004 del Frente Transversal Nacional y Popular (FTNyP). Estas organizaciones y dirigentes interpretaron el discurso de asunción presidencial y las primeras acciones de gobierno en la clave de las tres banderas del peronismo: independencia económica, soberanía política y justicia social (Pérez \& Natalucci, 2010). Su integración al movimiento tenía varias intencionalidades, una instrumental por el acceso a los recursos estatales, organizativa en términos de consolidar su posición como mediación política e identitaria por su reconocimiento como organizaciones sociales antes que piqueteras.

Durante 2004, la FTV, el MTD Evita, Barrios de Pie y el FTNyP se propusieron la construcción de un movimiento social kirchnerista que les permitiera posicionarse como un actor de consulta y decisión. Su expectativa era ganar un lugar en la nueva representación de las mayorías populares que se avizoraba. Para esto era necesario construir espacios de articulación política a través de los cuales pudieran erigirse como representantes de las demandas de los sectores de desocupados y trabajadores empobrecidos en el marco de una clase trabajadora fragmentada. A raíz de estas redefiniciones, modificaron su estrategia de confrontación que habían tenido hasta entonces con los gobiernos anteriores y se replegaron sobre el trabajo territorial. Debido a que los indicadores de desocupación, pobreza e indigencia todavía eran lo suficientemente altos como para prescindir de la ayuda social directa, las organizaciones tenían un significativo rol de mediación entre el gobierno nacional y los territorios. Desde esta perspectiva, se trataba de una relación de mutua necesidad ya que no solo las organizaciones necesitaban de ese acceso privilegiado a los recursos estatales, sino que el gobierno no contaba con llegada a ciertos territorios y dependía de aquellas para la implementación de ciertas políticas.

Indudablemente estas decisiones transformaron las formas de participación, sus alineamientos políticos y contribuyeron a revalorizar la figura de la representación institucional. Uno de los objetivos de ese movimiento social kirchnerista era integrar las listas del FPV en las elecciones legislativas de 2005. Sin embargo, diferencias en torno a la identidad peronista, el rol del Partido Justicialista como las relaciones de competencia entre las organizaciones por su conducción constituyeron obstáculos insalvables para su consolidación (Natalucci, 2015a). Ante esta situación, el MTD Evita impulsó el Movimiento Evita -nucleaba organizaciones nacionalpopulares- y Barrios de Pie impulsó a Libres del Sur -organizaciones referenciadas en la izquierda nacional-. La expectativa seguía siendo la misma: construir ese movimiento social 
Natalucci, A. (2018). La gramática movimentista durante el giro a la izquierda: El caso de Argentina. Revista de Sociología 33(1), 88-103. doi: 10.535/0719529X.2018.51796

kirchnerista que las erigiera como representantes de los sectores populares.

En relación con movimiento obrero, el proceso tuvo algunas similitudes. Inicialmente, debido a la efervescencia transversal y la situación de fragmentación de la CGT, el gobierno se relacionó con la CTA (Etchemendy, 2014). Sin embargo, el reacomodamiento al interior de la CGT y su representación sobre el sector privado modificaron esa situación inicial.

En 2003, la CGT estaba dividida en dos: Azopardo y Rebelde. La primera era presidida por Rodolfo Daer, en la que convivían tres nucleamientos: los gordos, los independientes, el MOP de afiliación menemista y Gremios Solidarios. La CGT Rebelde era conducida por el MTA (Natalucci \& Morris, 2016). Luego de las reuniones con Kirchner en junio de 2003, ambas empezaron un proceso de unificación de la CGT en pos de definir canales e interlocutores para la negociación. Ese proceso de unificación se extendió en dos etapas: en 2004 se eligió un triunvirato constituido por Susana Rueda Gordos-, Moyano -CGT Rebelde- y José Luis Lingieri -MOP-; y en junio de 2005, el Consejo Directivo consagró a Moyano como secretario general. La nueva CGT -cuyo esquema se mantuvo hasta 2012- expresaba básicamente la alianza entre el MTA y los independientes. Luego de esta reunificación, en una reunión con el gobierno, la CGT pidió la reactivación del consejo del salario mínimo vital y móvil y la restitución de las instancias paritarias, dos instituciones laborales que habían sido suspendidas en los noventa y que era claves para su reposicionamiento corporativo. Bajo estas condiciones, se selló la alianza con los sindicatos peronistas garantizando la representación de los trabajadores formales en la coalición kirchnerista. En este caso, como en las organizaciones sociales, fue decisivo el pasado de lucha contra el neoliberalismo que reportaba el MTA y Moyano.

Esta articulación política al interior del movimiento conmemoró el tercer aniversario del gobierno con una multitudinaria movilización en Plaza de Mayo. Participaron cerca de 120 mil personas, entre sindicatos, organizaciones sociales y partidarias. Este fue un momento de efervescencia para las organizaciones; las sociales lograron un crecimiento cuantitativo en sus filas, extensión territorial y cargos en la gestión de la política social. Las sindicales salieron del ostracismo que habían vivido en los noventa por la retracción del mundo del trabajo y la ofensiva del empresariado. Los sectores que habían resistido al neoliberalismo cobraban protagonismo y habían recuperado al peronismo como identidad política. Sin embargo, en todo movimiento de gramática movimentista opera una tensión entre la parte y el todo, que en algunas coyunturas se expresa entre representar sectorialmente y representar políticamente. En relación a esto último, las organizaciones tenían una evaluación negativa de su desempeño en el proceso electoral de 2005, ya que consideraban que no habían obtenido lugares expectantes en las listas legislativas. Su conclusión fue que era necesario activar un salto a la política, en el sentido de transformar su representación sectorial, su capital territorial, en representación política.

El salto a la política: protagonismo político y participación estatal

Ahora bien, ¿cuáles eran las implicancias del salto a la política que demandaban las 
Natalucci, A. (2018). La gramática movimentista durante el giro a la izquierda: El caso de Argentina. Revista de Sociología 33(1), 88-103. doi: 10.535/0719529X.2018.51796

organizaciones? ¿Remitía únicamente al protagonismo político en las instancias electorales o también incluía la participación estatal?

Según datos proporcionados por Farías Guizzo (2015) en las elecciones de 2005; 2007 y 2011 las organizaciones sociales tenían entre tres y cinco candidatos a diputados y los sindicatos dos; en 2013 por el caudal electoral del FPV solo dos integrantes de organizaciones accedieron a un escaño. La Cámpora, organización de jóvenes kirchneristas, tenía cuatro o cinco diputados propios, la misma cantidad de que el resto de las organizaciones y el doble que los sindicatos. Tanto las organizaciones sociales como las sindicales interpretaban que su participación en las instancias electorales no reflejaba su capital territorial y su capacidad de movilización. Aunque esa demanda era formulada por todas las organizaciones, variaba en su significado. Para el movimiento Evita la estructura partidaria debía reflejar la construcción territorial y social del kirchnerismo; al mismo tiempo que contar con diputados implicaba una mayor acumulación política territorial. Para Libres del Sur constituía la posibilidad de contar con diputados propios que les permitieran fortalecer la gestión de las políticas públicas. Para la FTV la escasa presencia en las listas se explicaba por el rechazo del partido justicialista a esta posibilidad. El FTNyP se mantuvo ausente en esta discusión ya que Edgardo Depetri, su máximo dirigente, logró ubicarse en un lugar expectante en las listas (Da Silva, 2012). Para la CGT Azopardo, de vertiente moyanista, era necesario restablecer la histórica cuota del 33\%, en un intento por resindicalizar al peronismo. Ahora bien, si se observan los números de legisladores, las organizaciones no tenían poca representación parlamentaria. Más bien lo que se entrevía era el decisionismo de la elite en la selección de los candidatos. Ante un movimiento con un bajo nivel de institucionalización, las relaciones de confianza preexistentes cobraban otra importancia.

En el marco de estos debates, algunas organizaciones decidieron crear nuevos espacios de articulación, como la corriente nacional del sindicalismo peronista y la juventud sindical de la corriente en 2009 -ambas moyanistas-y la corriente nacional de la militancia en 2010 -del movimiento Evita y dirigentes kirchneristas-. Sus principales objetivos eran construir una herramienta política para posicionarse ante las elecciones de 2011 en una especie de demostración de fuerza. De fondo, esta estrategia presentaba dos obstáculos. Por un lado, este tipo de construcción suponía una contigüidad entre posiciones sectoriales y representación política. Por otro, estos objetivos no necesariamente coincidían con los de la élite, siguiendo a Pérez (2013) esta no pretendía construir un "dispositivo institucional homogéneo de presión corporativa y penetración político-institucional" (p. 60), más bien buscaba generar un sentido de pertenencia sustentado sobre un conjunto de derechos e ideas de igualdad e integración. A la elite la baja institucionalidad del movimiento $y$ la precariedad de las mediaciones intrapartidarias le permitía cierta flexibilidad en las diferentes coyunturas. En este sentido, es poco probable que haya habido reparos ideológicos a la participación de las organizaciones en las listas, más bien pareciera que predominó una percepción sobre que su rol específico era la gestión de la política sectorial junto con un análisis instrumental en la cuestión electoral, 
Natalucci, A. (2018). La gramática movimentista durante el giro a la izquierda: El caso de Argentina. Revista de Sociología 33(1), 88-103. doi: 10.535/0719529X.2018.51796

indicado por las encuestas respecto del nivel de conocimiento público e imagen de los candidatos. Respecto de la participación de las organizaciones en el poder ejecutivo había diferencias entre los distintos tipos de organizaciones. Las sindicales canalizaban sus múltiples preocupaciones sectoriales en instituciones ya consolidadas como el consejo del salario o las negociaciones colectivas. Para Kirchner, el rol de aquellas era claro: "representar a los trabajadores en la puja por la distribución del ingreso" (Kirchner \& Di Tella, 2003, p. 66), antes que el ejercicio de cargos ejecutivos. El caso de las organizaciones sociales era diferente debido a su baja institucionalización y por las pocas capacidades estatales de intervención territorial. Siguiendo a Gómez (2010), el kirchnerismo no solo no podía prescindir de la capacidad de movilización sino tampoco de la contención a los sectores populares que las organizaciones brindaban. Su capital territorial era decisivo en la participación estatal, por ejemplo, muchas de las políticas implementadas desde el ministerio de desarrollo social fueron en consulta con las organizaciones mientras otras fueron diseñadas por ellas mismas. Por ello, Gómez (2010) señala que las organizaciones se erigieron como "una tecnología legítima de gestión estatal" (p. 83).

Asimismo, la capacidad de las organizaciones de mediar en la distribución de recursos asistenciales fue decisiva para la implementación de las políticas sociales, en parte atribuible a su concepción de militar el Estado. Esta frase era usada por las organizaciones y sus militantes para explicar su participación en áreas estatales, que implicaba no solo trabajar en ellas, sino también la posibilidad de erigirse como un puente entre los sectores populares y el Estado. Los militantes en el Estado eran una "garantía de compromiso con lo público" (Perelmiter, 2010, p. 146). Como bien señala Perelmiter (2016) la política social en tanto práctica supone una permanente toma de decisiones; por esta razón hay que mirar todas las micro decisiones que se ponen en juego y que definen su significado e impacto. $\mathrm{Y}$ en esta última, las organizaciones cumplieron un rol fundamental.

Resumiendo, las organizaciones en la gestión eran una parte fundamental en la implementación de políticas públicas y en la construcción de una narrativa que sostenía la restitución de las capacidades estatales. Sin embargo, la demanda sobre el salto a la política se instaló como una disputa al interior del kirchnerismo que fue debilitando su capacidad articulatoria.

La progresiva desarticulación de la gramática movimentista

Néstor Kirchner falleció el 27 de octubre de 2010, por lo que Fernández de Kirchner asumió el liderazgo del movimiento político. Pocos días antes, durante el acto por el Día de la Lealtad, Moyano había insistido con que el sindicalismo había recuperado su poder gremial, pero necesitaba reasumir el poder político que había tenido otrora. En el final de su discurso mencionó que su sueño era que un trabajador ocupara la Casa Rosada. Fernández de Kirchner quién tomó la palabra luego dijo taxativamente que ella trabajaba desde muy joven, de alguna manera intentando anular ese argumento. Las controversias no eran nuevas, habían emergido a propósito de la crisis internacional de 2008 y 2009. Como se mencionó en la introducción, esa 
Natalucci, A. (2018). La gramática movimentista durante el giro a la izquierda: El caso de Argentina. Revista de Sociología 33(1), 88-103. doi: 10.535/0719529X.2018.51796

crisis quebró la situación de win`win donde todos los sectores mejoraban sus condiciones. Por múltiples motivos, el kirchnerismo en vez de introducir reformas estructurales se dedicó a gestionar la crisis. De esta manera, empezaron a emerger críticas internas respecto de la eficacia de políticas públicas, el manejo de la economía y la distribución de la riqueza. Este proceso interno y el estilo de liderazgo de Fernández de Kirchner fueron decisivos para que la elite política pensara en la ampliación de la fuerza propia es decir, de la incorporación de dirigentes puramente kirchneristas y de la creación de organizaciones que respondieran de modo directo a la presidenta.

Ahora bien, esa decisión no implicaba una mayor institucionalización del movimiento, sino una progresiva desarticulación de la gramática movimentista con sucesivas rupturas organizacionales y la emergencia de relaciones de competencia entre las organizaciones que permanecieron en él. De fondo lo que estaba en discusión era qué sujetos estaban autorizados para hacer política, que fue importante para la suspensión progresiva de las mediaciones organizacionales. De modo insistente, Fernández de Kirchner declaraba que tenía un trato directo con los trabajadores y los sectores populares y que no necesitaba de las organizaciones para sostener ese vínculo. El resultado electoral de las presidenciales de 2011 fue decisivo para reforzar ese imaginario, ese $54 \%$ de los votos eran propios de Cristina. Esta construcción simbólica fue acompañada de los siguientes acontecimientos: el fortalecimiento de la Cámpora como parte de la élite política, el intento de desplazar a Moyano de la conducción de la CGT, que llevó a su ruptura, y el lanzamiento del frente unidos y organizados que intentaban ubicar a la corriente nacional de la militancia bajo la conducción camporista.

Haciendo una breve recapitulación, la idea de la Cámpora había surgido a fines de 2006; por ese entonces Kirchner sostenía que era necesario formar una organización de 500 cuadros políticos que gobernara Argentina por los próximos lustros. Incluso su primer nombre era juventud del FPV. Su objetivo era convocar a la generación que en los noventa había militado y a jóvenes sin práctica militante pero atraídos por la interpelación que el kirchnerismo construía alrededor de lo juvenil. Su visibilidad pública coincidió con el conflicto con las entidades agropecuarias, en el cual la organización impulsó una campaña de información y concientización. En una primera etapa, La Cámpora funcionó como un espacio de coordinación de intervenciones callejeras de las diferentes organizaciones que participaban. El punto de inflexión sucedió en septiembre de 2010 a propósito de la organización del acto de la juventud. Por ese entonces, Kirchner sostenía la necesidad de conformar un único espacio de juventudes que nucleara a la Cámpora, la JP Evita y la juventud sindical. Sin embargo, en el acto las ubicaciones centrales fueron ocupadas por dirigentes de las organizaciones que ya integraban la Cámpora, dejando a un margen a las otras.

La segunda etapa de la Cámpora se inició luego del fallecimiento de Kirchner. Por un lado, tuvo un brutal crecimiento cuantitativo, miles de jóvenes sin experiencia previa se incorporaron a la organización; sin tradiciones propias, el kirchnerismo se convertía en su experiencia política originaria. Por otro lado, fue clave el reconocimiento reiterado de Fernández de Kirchner como la organización oficial. Ambos 
Natalucci, A. (2018). La gramática movimentista durante el giro a la izquierda: El caso de Argentina. Revista de Sociología 33(1), 88-103. doi: 10.535/0719529X.2018.51796

factores incidieron en el rediseño del perfil de la organización, ya no sería solo para el apoyo callejero, sino fundamental para la gestión.

Una diferencia entre la Cámpora y otras organizaciones es que aquella no pretendía construirse como un puente, sino en representante del kirchnerismo en los territorios a partir de la acción estatal; en este sentido, su lógica era la misma que la de la élite política. Esto propició su incorporación a un "dispositivo de poder ya en funcionamiento" (Natanson, 2012, p. 20), sus dirigentes participaban de la mesa chica kirchnerista, espacio donde se tomaban las decisiones estratégicas y se seleccionaban funcionarios y candidatos. Por estas razones, su ethos militante -en términos de disposiciones subjetivas para la acción- implicaba la formación de cuadros políticos orientados a la gestión estatal. En definitiva, la consolidación de La Cámpora tuvo como correlato un fuerte proceso de identificación simbólica entre sus militantes y Fernández de Kirchner, que se escenificaba en los rituales conocidos como los patios militantes (Rocca Rivarola, 2016). En los patios los militantes se encontraban con Cristina. Esta identificación ha sido tan fuerte que ha perdurado aún luego de la sucesión presidencial en 2015 .
Como contracara de este proceso de fortalecimiento de la fuerza propia, se produjo la desarticulación de la gramática movimentista, construida a partir de relaciones radiales con Kirchner, implicando una contracción de la base de alianzas. En 2012 se quebró la alianza con Moyano y aunque se conformó la CGT Alsina de afiliación kirchnerista, se construyó una brecha con los trabajadores formales, que una de sus expresiones fue la derrota electoral de 2013 en la provincia de Buenos Aires, donde triunfó el Frente Renovador. A su vez, organizaciones sociales conformaron la confederación de trabajadores de la economía popular que, aunque no tenía un discurso crítico hacia el kirchnerismo, expresaba demandas a problemas que aquel no había podido resolver.

La reducción de las alianzas fue una expresión de la desarticulación de la gramática movimentista y al mismo tiempo una limitación para el discurso prometeico del kirchnerismo. La incapacidad para absorber o resolver nuevas demandas generó una dinámica autorreferencial que valorizaba el pasado reciente y la resolución de la crisis de 2001, sin poder ofrecer una propuesta orientada al futuro. Este ciclo se cerró con la derrota electoral en las presidenciales de 2015.

\section{DISCUSIÓN Y CONCLUSIONES}

El objetivo de este ensayo fue analizar una de las novedades del giro a la izquierda: la capacidad de articulación política de los gobiernos y los modos en que se reinventaron las relaciones con las organizaciones. Para esto nos detuvimos sobre la recreación de la gramática movimentista de acción política para dilucidar las relaciones entre la elite kirchnerista $\mathrm{y}$ las organizaciones. Aunque el caso empírico analizado fue el argentino, el ensayo brinda una perspectiva analítica para abordar otros casos de la región. 
Natalucci, A. (2018). La gramática movimentista durante el giro a la izquierda: El caso de Argentina. Revista de Sociología 33(1), 88-103. doi: 10.535/0719529X.2018.51796

El kirchnerismo fue al mismo tiempo un gobierno y un movimiento político, integrado principalmente por una elite, organizaciones de base territorial y sindicales. Por las características de la elite tuvo un bajo nivel de institucionalización y un liderazgo central alrededor de la figura de Kirchner. Aunque este sostuviera una lógica decisionista y relativamente de desincentivar mediaciones internas, impulsaba a la movilización como modo de dirimir conflictos. Las organizaciones que participaron de ese movimiento tenían características en común: capacidad de movilización, de creación de demandas a partir de intereses sectoriales, capital territorial y un pasado de lucha contra el neoliberalismo. Sobre este último se construyó una alianza programática con la elite que permitía marcar una ruptura respecto de los noventa. En este punto queda claro que su incorporación no solo respondió a la obtención de recursos materiales según una lógica instrumental.

Ese movimiento se consolidó entre 2007 y 2010, donde las organizaciones crecieron en número, mejoraron sus posiciones sectoriales e intentaron incrementar su protagonismo político en las instancias electorales. Una evaluación de este proceso las llevó a plantear la demanda del salto a la política, como estrategia para transformar su representación sectorial en representación política. Ahora bien, en una gramática movimentista hay una tensión constitutiva entre la parte y el todo, que en algunas coyunturas se expresa entre representar sectorialmente y representar políticamente. Estas tensiones se fueron agudizando según las diferentes coyunturas y las respuestas de cada espacio.

A partir de 2010 esa gramática se fue desarticulando por el fallecimiento de Kirchner que privó al movimiento de un liderazgo fuerte, el nombramiento de la Cámpora como organización oficial y diferencias respecto de cómo procesar la crisis internacional de 2008 y 2009 y la política económica a seguir. Frente a este escenario, la decisión de Fernández de Kirchner fue apostar a la construcción de una fuerza propia, con la cual fortalecer su representación sobre los sectores populares, pero que no desafiara su liderazgo ni tuviera ambiciones por fuera del movimiento. Aunque esa gramática se desarticuló, lo cierto es que las organizaciones salieron fortalecidas del proceso en el sentido que obtuvieron legisladores, crecieron cuantitativamente, aprendieron a gestionar oficinas y programas estatales, en definitiva, ampliaron sus capacidades territoriales, políticos e institucionales.

El kirchnerismo como movimiento político no estuvo exclusivamente determinado por las intenciones de su elite, sino también por las experiencias y expectativas de las organizaciones que participaron. Por un lado, el kirchnerismo significó una oportunidad política y una posibilidad identificatoria. Sin embargo, a partir de este proceso las identidades políticas se fueron resignificando y así como algunos recuperaron al peronismo, otros empezaron a definir su identidad entre kirchneristas y peronistas, que tensionó la dinámica interna según como se denominara cada sector. Por otro lado, aunque las relaciones al interior del 
Natalucci, A. (2018). La gramática movimentista durante el giro a la izquierda: El caso de Argentina. Revista de Sociología 33(1), 88-103. doi: 10.535/0719529X.2018.51796

movimiento no solo fueron instrumentales, sino también programáticas y de articulación, las organizaciones no parecían dispuestas a diluir sus estrategias y organizaciones en función de lo que indicara el líder. Las experiencias durante los noventa habían configurado sus pautas de acción en las que pretendían conservar un margen de autonomía tanto en cuestiones identitarias como de construcción política. Sobre estas se asentó esa diferencia constitutiva de la gramática movimentista de lo sectorial y lo político. Y sobre tensión se dirimió la trayectoria del movimiento. La última cuestión para mencionar es que la desarticulación de la gramática movimentista fue clave para el deterioro político de los gobiernos y su innovación política, que los ubicó en una situación de debilidad en contiendas electorales, pero también para esa representación política que habían logrado construir.

Este punto es fundamental para entender el proceso argentino en perspectiva a la región. Por un lado, esa fortaleza que adquirieron las organizaciones les permitió transitar el giro a la derecha. Por otro lado, esa desarticulación de la gramática movimentista no fue total, por lo que el kirchnerismo sigue siendo un actor político de relevancia, incluso en las contiendas electorales. El kirchnerismo, a diferencia de otros casos del giro a la izquierda como la del chavismo en Venezuela o la del MAS en Bolivia, no avanzó en procesos de reforma constitucional que redelinearan las reglas institucionales del juego político. Asimismo, tampoco ha sido muy creativo en la instalación de imaginarios transgresores como lo han sido las ideas del socialismo de siglo XXI o la del Estado plurinacional. Aun así, produjo cambios en la cultura política local y en las disposiciones para la acción política no solo de la izquierda o del nacionalismo popular, sino también de la derecha. Una de ellas, fue el traspaso de mando de una fuerza política a otra en diciembre de 2015 sin que mediara una crisis, algo inédito desde la transición democrática considerando las coyunturas políticas de 1989 y 2001; marcando una diferencia significativa con la experiencia brasileña reciente. Para finalizar, resta mencionar que los estudios nacionales pormenorizados constituyen un elemento significativo para complejizar los procesos regionales que de manera cíclica atraviesa América Latina. En pos de su consistencia, las miradas comparativas suelen desdibujar $u$ omitir ciertos elementos locales. Si adoptamos una clave de complementariedad, los estudios locales pueden aportar algunas pistas acerca de cómo se reconstituyen esas dinámicas en los vaivenes políticos.

\section{REFERENCIAS}

Álvarez, S., Rubin, J., Thayer, M., Baiocchi, G., \& Laó-Montes, A. (2017). Beyond civil society. Activism, participation and protest in Latin America. Durham, Inglaterra: Duke University Press. 
Natalucci, A. (2018). La gramática movimentista durante el giro a la izquierda: El caso de Argentina. Revista de Sociología 33(1), 88-103. doi: 10.535/0719529X.2018.51796

Barros, S. (2010, septiembre). Identificación populista, espacio y democracia. Trabajo presentado en el II Encuentro entre Equipos de Investigación en Teoría Política, CEACONYCET, Córdoba, Argentina.

Bourdieu, P. (1982). La represéntation politique. É1lements pour une théorie du champ politique. Actes de la Recherche en Sciences Sociales, 36(36-37), 3-24.

Cheresky, I. (2006). Ciudadanía, sociedad civil, y participación política. Buenos Aires, Argentina: Miño y Dávila.

Da Silva, M. L. (2012). Cooptados por las ideas. El Frente Transversal Nacional y Popular (2003-2011). En G. Pérez, \& A. Natalucci (Eds.), "Vamos las bandas..." Organizaciones y militancia kirchnerista (pp. 85-116). Buenos Aires, Argentina: Nueva Trilce.

Etchemendy, S. (2014). La "doble alianza" gobierno-sindicatos en el kirchnerismo (2003-2012): Orígenes, evidencia y perspectivas. En C. Acuña (Ed.), ¿Cuánto importan las instituciones? (pp. 291-324). Buenos Aires, Argentina: Siglo XXI Editores.

Farías Guizzo, J. (2015). Bancando el proyecto. El Frente para la Victoria y su relación con los movimientos sociales y el Partido Justicialista. Manuscrito no publicado, Facultad de Ciencias Sociales, Universidad de Buenos Aires, Buenos Aires, Argentina.

Ferrero, J. P., Natalucci, A., \& Tatagiba, L., (En prensa). The socio-political dynamics within the crisis of the left turn: Argentina and Brazil. Londres, Inglaterra: Rowman and Littlefiel.

Germani, G. (1966). Política y sociedad en una época en transición. De la sociedad tradicional a la sociedad de masas. Buenos Aires, Argentina: Paidós.

Germani, G. (1978 | 2003). Autoritarismo, fascismo y populismo nacional. Buenos Aires, Argentina: Temas.
Gómez, M. (2009). Las políticas de empleo como respuesta estatal a la acción colectiva de los movimientos de desocupados. Entre el clientelismo, el "empowerment" y la lucha política. En. M. Gómez, \& A. Massetti (Eds.), Los movimientos sociales dicen. Conversaciones con dirigentes piqueteros sobre el proyecto nacional y latinoamericano (pp. 119-154). Buenos Aires, Argentina: Nueva Trilce.

Gómez, M. (2010). Acerca del protagonismo político y la participación estatal de los movimientos sociales populares: Falacias, alucinaciones y cegueras del paradigma normal de análisis. En A. Massetti, E. Villanueva, \& M. Gómez (Eds.), Movilizaciones, protestas e identidades políticas en la Argentina del Bicentenario (pp. 65-94). Buenos Aires, Argentina: Nueva Trilce

Kirchner, N. (2003). Discurso de asunción. Recuperado https://www.lanacion.com.ar/498849-eltexto-completo-del-discurso-presidencial.

Kirchner, N., \& Di Tella, T. S. (2003) Después del derrumbe. Teoría y práctica política en la Argentina que viene. Conversaciones con Néstor Kirchner. Buenos Aires, Argentina: Galerna.

Natalucci, A. (2015a). Mobilização social e mudanças políticas: Revisitando o conceito de gramáticas de ação política. Plural, 22(1), 83-106. doi: 10.11606/issn.21768099.pcso.2015.102215

Natalucci, A. (2015b). Corporativismo y política: dilemas del movimiento obrero durante el kirchnerismo. Revista Población \& Sociedad, $22(2), 5-25$.

Natalucci, A., \& Morris, B. (2016). La unidad de la CGT en prospectiva (2004-2016). Revista Socio Debate 2(4), 33-62.

Natanson, J. (2012). ¿Por qué los jóvenes están volviendo a la política? De los indignado a La Cámpora. Buenos Aires, Argentina: Debate. 
Natalucci, A. (2018). La gramática movimentista durante el giro a la izquierda: El caso de Argentina. Revista de Sociología 33(1), 88-103. doi: 10.535/0719529X.2018.51796

Offerlé, M. (2011). Los oficios, la profesión y la vocación de la política. PolHis, 4(7), 84-99.

Ortiz de Rozas, V. (2011). Las formas de reclutamiento del personal político, una vía de entrada al estudio del régimen político provincial. Santiago del Estero (1999-2009). Perspectivas de Políticas Públicas 1(1), 133159. doi: 10.18294/rppp.2011.647

Perelmiter, L. (2010). Militar el estado. La incorporación de movimientos sociales de desocupados en la gestión de políticas sociales. Argentina (2003-2008). En A. Massetti, E. Villanueva, \& M. Gómez (Eds.), Movilizaciones, protestas e identidades políticas en la Argentina del bicentenario (pp. 137-172). Buenos Aires, Argentina: Nueva Trilce.

Perelmiter, L. (2016). Burocracia plebeya. Buenos Aires, Argentina: UNSAM Edita.

Pérez, G. (2007). Participación, cambio social y régimen político. Apuntes sobre dos ciclos de movilización. En E. Rinesi, \& G. Vommaro. Los lentes de Víctor Hugo. Transformaciones políticas y desafios teóricos en la Argentina reciente (pp. 271-312). Buenos Aires, Argentina: Prometeo.

Pérez, G., \& Natalucci, A. (2010). La matriz movimentista de acción colectiva en Argentina: La experiencia del espacio militante kirchnerista. América Latina Hoy, 54, 97-112.

Pérez, G., \& Natalucci, A. (2012). Vamos las bandas. Organizaciones y militancia kirchnerista. Buenos Aires, Argentina: Nueva Trilce.

Rocca Rivarola, D. (2016, septiembre). "Con Néstor y Cristina, todo el año es carnaval": Notas sobre prácticas y mensajes en actos militantes del kirchnerismo. Trabajo presentado en el XII Congreso Nacional y V Congreso Internacional sobre Democracia,
Universidad Nacional de Rosario, Rosario, Argentina. Resumen recuperado de https://www.conicet.gov.ar/new_scp/detalle. php?keywords=\&id=36674\&congresos=yes \&detalles=yes\&congr_id $=6232130$

Rossi F. (2017). The poor's struggle for political incorporation. Cambridge, Reino Unido: Cambridge University Press.

Sidicaro, R. (2011). El partido peronista y los gobiernos kirchneristas. Nueva Sociedad, 234, 75-94.

Silva, E. (2017). Reorganizing popular sector incorporation: Propositions from Bolivia, Ecuador, and Venezuela. Politics and Society, 45(1), 91-122. doi: $10.1177 / 0032329216683166$

Sosa P. (2016). Los orígenes de las concepciones políticas del kirchnerismo. La experiencia política del Ateneo Juan Domingo Perón en la provincia de Santa Cruz (1981-1987). Temas y Debates, Rosario, 20(32), 77-96.

Stefanoni, P. (2016). ¿Alba o crepúsculo? Geografías y tensiones del socialismo del siglo XXI. En M. Rodríguez (Ed.), ¿Por qué retrocede la izquierda? (pp. 81-117). Buenos Aires, Argentina: Capital Intelectual.

Torre, J. C. (2005). La operación política de la transversalidad. El presidente Kirchner y el Partido Justicialista. En CEDIT (Comp.), Argentina en perspectiva. Reflexiones sobre nuestro país en democracia (pp. 22-31). Buenos Aires, Argentina: La Crujía Ediciones.

Wainer A. (2018). Economía y Política en la Argentina Kirchnerista (2003-2015). Revista Mexicana de Sociología, 80(2), 329-345. doi: 10.22201/iis.01882503p.2018.2.57720

Manuscrito recibido: 31-08-2018

Manuscrito aceptado: 28-11-2018 